\title{
PROFESSOR OU INSTRUTOR? REFLEXÃO SOBRE A PROFISSÃO DO EDUCADOR SURDO
}

TEACHER OR INSTRUCTOR? REFLECTION ON THE PROFESSION OR THE DEAF EDUCATOR

\author{
Daniele Silva Rocha* \\ Lilian Cristine Ribeiro Nascimento**
}

\section{Resumo}

O propósito deste artigo é apresentar questões relativas à profissão do educador surdo, examinando a legislação, principalmente no que diz respeito ao vínculo empregatício, pois muitos profissionais surdos, formados e qualificados como docentes, são contratados como instrutores. Para problematizar a expressão "instrutor de Libras", atribuída aos profissionais surdos que ensinam Libras, analisamos editais de concursos públicos que trazem em seu texto a expressão "instrutor surdo". Defendemos a autonomia do professor em suas práticas pedagógicas, ancoradas em uma formação específica e pontuamos a necessidade de diferenciar os termos "instrutor de Libras" e "professor", para valorizar o trabalho de docência e, sobretudo, para dar visibilidade e espaço ao professor surdo.

Palavras-chaves: Professores surdos. Educação bilíngue de surdos. Prática docente.

Desde a promulgação do Decreto $\mathrm{n}^{\mathrm{o}}$ 5.626/2005, que insere a Libras como disciplina curricular obrigatória nos cursos de formação de professores e nos cursos de Fonoaudiologia, tem aumentado a oferta de concursos públicos ou vagas de trabalho docente nas universidades privadas e na educação básica para docentes proficientes em Libras, encarregados de ministrar essa disciplina. Essa oferta de trabalho abriu oportunidades para pessoas surdas, usuárias de Libras, que passaram a procurar formação acadêmica a fim de ocupar essas vagas. O Decreto $n^{\circ}$ 5.626/05 prevê a formação desses

\footnotetext{
* Mestre em Educação pela Universidade Estadual de Campinas (UNICAMP), Campinas, São Paulo, Brasil. E-mail: danirocha20@gmail.com

** Doutora em Educação pela Universidade Estadual de (UNICAMP), Campinas, São Paulo, Brasil. Email: lilianrn@unicamp.br
} 
profissionais e os distribui em três categorias: I - professor de Libras; II - instrutor de Libras; III - professor ouvinte bilíngue: Libras - Língua Portuguesa (BRASIL, 2005).

Na primeira categoria - professor de Libras - o profissional deve ter como perfil: ser usuário dessa língua e ter cursado pós-graduação ou ter formação superior aliada ao certificado de proficiência ${ }^{1}$ em Libras. A segunda categoria - instrutor em Libras - deve ter nível médio de formação e certificado de proficiência em Libras. Já a última categoria - professor ouvinte bilíngue - exige que o profissional tenha cursado pós-graduação ou tenha formação superior e certificado de proficiência em Libras (BRASIL, 2005).

A possibilidade de formação de instrutores de Libras no ensino médio foi prevista pelo Decreto, uma vez que atendia a uma necessidade urgente, naquele momento, de profissionais para o mercado de trabalho, a fim de garantir a execução de implementação de escolas e classes bilíngues, em que a Libras fosse ensinada aos alunos e utilizada como língua de instrução. Observa-se, porém, que o Decreto prevê que o instrutor seja "usuário dessa língua com formação de nível médio e com certificado obtido por meio de exame de proficiência em Libras, promovido pelo Ministério da Educação" (BRASIL, 2005).

O que buscamos problematizar neste artigo é o fato de a nomenclatura "instrutor de Libras" ainda ser atribuída aos profissionais surdos que ensinam Libras e que, mesmo tendo concluído a graduação, são contratados com a denominação de “instrutor". Para tal, apresentamos e analisamos editais de concursos públicos que trazem em seu texto a denominação "instrutor surdo". Antes disso, faremos uma reflexão teórica sobre a função do professor.

De acordo com Saviani (1996), o professor é aquele que educa, o qual precisa também aprender, ser formado para ser educador, e usar os saberes implicados na ação de educar. Segundo o autor: "em lugar de os saberes determinarem a formação do educador, é a educação que determina os saberes que entram na formação do educador" (SAVIANI, 1996, p.145). Dessa forma, o professor precisa estar sempre em reflexão, em sala de aula e fora dela, para que os tipos de saberes determinem uma visão de mundo, uma concepção de educação, de ensino, enquanto na sala de aula, como prática do docente, o professor é visto como "espaço de produção da competência profissional pelos próprios professores" (TARDIF, 2010, p. 291). O trabalho do professor, tanto coletiva quanto individualmente, é o lugar em que se produzem saberes, adquiridos pela reflexão prática sobre as atividades cotidianas de ensino na escola. 
Continuando com as palavras de Tardif (2010, p. 234), o trabalho dos professores é "um espaço específico de produção, de transformação e de mobilização de saberes, e, portanto, de teorias, de conhecimentos e de saber-fazer específicos ao ofício de professor". Para compreender esse postulado, faz-se necessário esclarecer a formação do profissional surdo, como deve ser o "saber" científico e o conhecimento específico da sua formação.

Na educação de crianças e jovens surdos, é de suma importância a presença física do educador surdo em sala de aula. Com ele o aluno surdo não só aprende a língua de sinais, mas também, através da identificação, desenvolve uma subjetividade pautada na positividade da sua condição de ser surdo (MARTINS e LACERDA, 2016). Além desse aspecto, o educador surdo tem domínio de metodologias a serem utilizadas e adaptadas, o que impulsiona o interesse dos alunos quando o conteúdo acadêmico é trabalhado por meio de estratégias visuais. Na presença desse profissional, o ambiente linguístico se torna rico, o que permite que ele tenha melhor aproveitamento no processo de ensino e aprendizagem. O trabalho bilíngue, portanto, deve ter qualidade, o que se produz a partir de uma formação adequada do professor. A formação do professor "é um processo pedagógico, intencional e organizado, de preparação teórico-científica e técnica do professor para dirigir competentemente o processo de ensino" (LIBÂNEO, 1994, p.27).

As crianças surdas que têm oportunidade de ter contatos com os profissionais surdos em sala de aula, tem uma otimização na construção de conhecimento, uma vez que a interação linguística favorece seu desenvolvimento, como afirma Vygotsky (1998). O profissional surdo faz a função de mediador, favorecendo a construção de palavra, ou seja, o signo, que é o elemento mais importante do pensamento e da cultura humana. Embora profissionais ouvintes, fluentes em Libras, possam também ser mediadores na aprendizagem e desenvolvimento das crianças surdas, a maioria deles não tem a língua de sinais como sua língua natural.

Reafirmamos, portanto, a importância de a criança surda ter contato com educadores surdos. É preocupante a situação de uma criança surda inserida em uma escola onde não há professor surdo, sem poder compartilhar sua língua com seus colegas e professores (BOTELHO, 1998; LACERDA, 1999). Nesse ambiente a língua dominante é o português. As crianças ouvintes se comunicam espontaneamente, e a criança surda, nesse contexto, não aprende a sua língua. Como podem se constituir enquanto sujeito, ou 
seja, desenvolver sua subjetividade no período de aquisição da linguagem sem poder interagir em uma língua compreensível?

Bakhtin (1999) ressalta que o sujeito se constrói na interação com os outros, o que pressupõe que a linguagem sempre coloca sujeitos e sentidos em relação, não havendo, portanto, linguagem sem interação. De acordo com Bakhtin (1999), a linguagem é dialógica, sendo a base da constituição humana. A linguagem é, portanto, sempre social.

Reis (2007) descreve os conceitos de identificação e modelo na questão do professor surdo na sala de aula, e enfatiza a importância desse profissional em contato com o aluno surdo. A autora também destaca o papel do professor ouvinte no processo educacional do aluno surdo, mas alerta para a necessidade da presença física do professor surdo para que esse aluno construa os seus valores como sujeito surdo. Reis (2007, p. 96) sugere que os professores surdos não sejam dependentes dos outros professores ouvintes, mas que manifestem suas singularidades no processo pedagógico. Segundo Reis (2007), somente desse modo, os alunos poderão ter uma identificação positiva com seus professores surdos.

Neste artigo, buscamos dar visibilidade à forma como a inserção desse educador surdo se operacionaliza a partir de editais de concursos públicos e credenciamento para o preenchimento de cargos de instrutor ou professor surdo. A análise desse material se faz útil para a reflexão e discussão a respeito do cargo em que o profissional surdo está inserido no mercado de trabalho. Nesse material, analisamos também a relação entre docência e a formação do profissional surdo.

Quadro 1. Prefeitura Municipal de Barueri (SP)

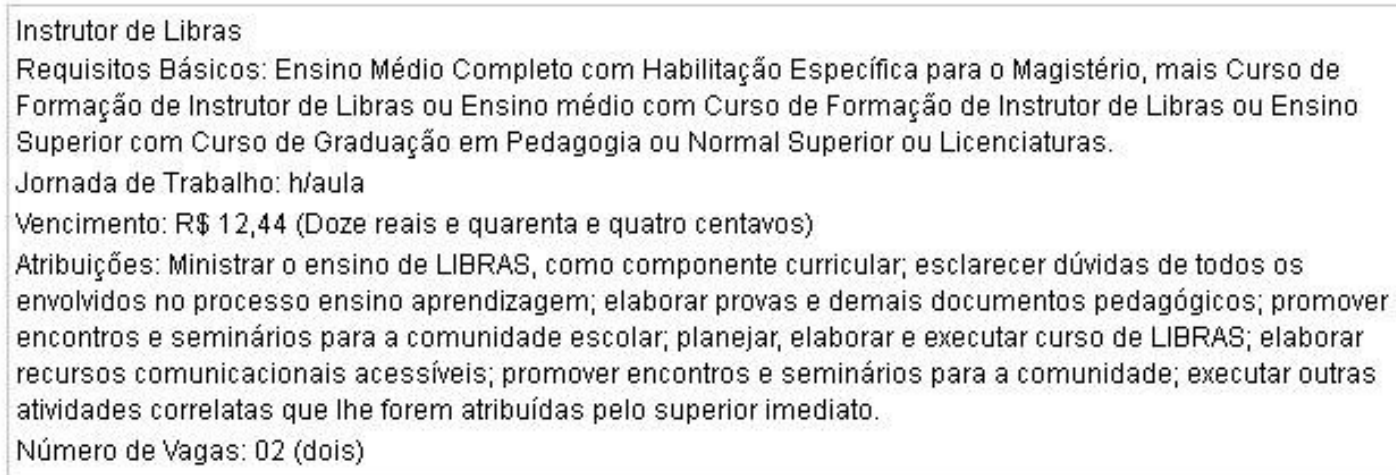

Fonte: Edital $n^{\circ}$ PMB 02/20, de 7 de outubro de $2011^{2}$. 
Quadro 2 . Prefeitura Municipal de Petrópolis (RJ)

1.2. O Concurso Público destina-se a selecionar candidatos para o provimento de vagas relacionadas no quadro de vagas constantes abaixo:

\begin{tabular}{|c|c|c|c|c|c|c|}
\hline \multirow[b]{2}{*}{ NÍVEL } & \multirow[b]{2}{*}{ CARGO } & \multicolumn{5}{|c|}{ VAGAS } \\
\hline & & REGIÃO & AC & NI & PCD & TOTAL \\
\hline \multirow{4}{*}{ MÉDIO } & \multirow{2}{*}{ CUIDADOR ESCOLAR } & 1롤 & 7 & 2 & 1 & 10 \\
\hline & & 2a & 4 & 1 & 0 & 5 \\
\hline & \multirow{2}{*}{ INTÉRPRETE DE LIBRAS } & 1a & 4 & 1 & 0 & 5 \\
\hline & & 2a & 2 & 0 & 0 & 2 \\
\hline \multirow{5}{*}{ SUPERIOR } & INSTRUTOR DE LIBRAS & + & 2 & 0 & 0 & 2 \\
\hline & \multirow{2}{*}{ PROFESSOR DA EDUCAÇÃO BÁSICA (ANOS INICIAIS) } & 1a & 75 & 20 & 5 & 100 \\
\hline & & $2^{a}$ & 37 & 10 & 3 & 50 \\
\hline & \multirow{2}{*}{ PROFESSOR DA EDUCAÇÃO BÁSICA (MATEMÁTICA) } & 12 & 15 & 4 & 1 & 20 \\
\hline & & 2a & 7 & 2 & 1 & 10 \\
\hline \multicolumn{3}{|c|}{ TOTAL DE VAGAS } & 153 & 40 & 11 & 204 \\
\hline
\end{tabular}

Requisitos para o provimento do cargo de Instrutor de LIBRAS

Os requisitos para o cargo de Instrutor de Libras compreendem a certificação de conclusão do Ensino Superior com licenciatura;

- Certificação conferida por exame Prolibras/MEC - com proficiência em Tradução e Interpretação de Libras - Língua Portuguesa;

- Curso de instrutor de Libras ou assistente educacional de Libras, promovido por instituição reconhecida;

- Comprovar boas condições de saúde, mediante atestado médico;

- Declarar disponibilidade para 20 horas semanais.

Fonte: Edital no 001/2014, de 19 de dezembro de $2014^{3}$.

Quadro 3. Prefeitura Municipal de Santo Ângelo (RS)

\section{DOS CARGOS, REQUISITOS PARA PROVIMENTO, VAGAS, CARGA HORÁRIA E VENCIMENTO. \\ INSTRUTOR DE Curso Superior Completo na área da educaçăo com formaçẵo e $01+$ \\ LIBRAS \\ Proficiência em Libras, quando da posse.

\begin{tabular}{l|l|l}
$01+$ & 30 & 5,34 \\
$C R$ & 30 & PRM
\end{tabular}

Fonte: Edital no 58/2010, de 7 de janeiro de $2010^{4}$.

Quadro 4. Prefeitura Municipal de São Caetano do Sul (SP)

\begin{tabular}{|c|c|c|c|c|c|c|c|c|c|}
\hline & & \multicolumn{5}{|c|}{$\begin{array}{l}\text { ANEXOI } \\
\text { DOS CóDIGOS, EMPREGOS, VAGAS, VAGAS PARA PORTADORES DE DEFICIÊNCIA, CADASTRO DE RESERVA, } \\
\text { REQUISITOS, REMUNERAÇÃOO, GRATIFICAÇã̃O SUS, CARGA HORÁRIA E TAXA DE INSCRIÇÃO }\end{array}$} & & & \\
\hline cód. & EMPREGOS & $\begin{array}{l}\text { TOTAL DE } \\
\text { VAGAS }\end{array}$ & \begin{tabular}{|l|} 
VAGAS PARA \\
PORTADORS \\
DE \\
DEFICIENCIA
\end{tabular} & $\begin{array}{l}\text { CADASTRO } \\
\text { DE RESERVA }\end{array}$ & REQUISITOS & REMUNERAÇ̧̄̃o* & $\begin{array}{l}\text { GRATIFICACÃ̃o } \\
\text { SUS"* }\end{array}$ & $\begin{array}{l}\text { CARGA } \\
\text { HORÁRIA } \\
\text { SEMANAL } \\
\end{array}$ & $\begin{array}{l}\text { TAXA DE } \\
\text { INSCRIÇắ }\end{array}$ \\
\hline 71 & INSTRUTOR DE LBRAS & 1 & . & 5 & Nivel Superior completo e curso especifico na área & R\$2.049,75 & & 44 & $R \$ 60,00$ \\
\hline
\end{tabular}

Fonte: Edital no 001/2015, de 4 de março de $2016^{5}$. 
Quadro 5. Prefeitura do Município de São Paulo (SP)

\section{DAS CONDIÇŌES DE CREDENCIAMENTO}

7.1 São requisitos mínimos para o credenciamento:

7.1.1 Profissional prioritariamente surdo, de nível superior ou médio com idade mínima de 18 anos;

7.2 Os interessados em atuar como Instrutores de Libras deverão apresentar no momento da inscrição:

7.2.1 Cópia do certificado de conclusão do Ensino Médio ou do Ensino Superior:

7.2.2 Cópia do certificado de aprovação no PROLIBRAS/ MEC, no uso e no ensino da Libras; ou Cópia do certificado de aprovação no PROLIBRAS/MEC, na categoria usuário de Libras, surdos; ou certificado de conclusāo de graduaçāo em Letras/ Libras ou certificado de curso de Pós-Graduação em Libras;

7.2.3 Cópia RG ou $\mathrm{CNH}$;

7.2.4 Cópia do CPF:

7.2.5 Comprovante de situaçāo cadastral do CPF, que pode ser obtido no Portal da Receita Federal (wwww.receita.fazenda.gov.br);

7.2.6 Comprovante de endereço;

7.2.7 Currículo atualizado;

Fonte: Edital de Credenciamento SME/Divisão de Educação Especial - DIEE nº 01/2016 ${ }^{6}$.

Quadro 6. Prefeitura Municipal de Vitória (ES)

\begin{tabular}{|c|c|}
\hline \multicolumn{2}{|c|}{ 4-PROFESSOR DE EDUCAÇÃO BÁSICA - LIBRAS } \\
\hline REQUISITOS: & 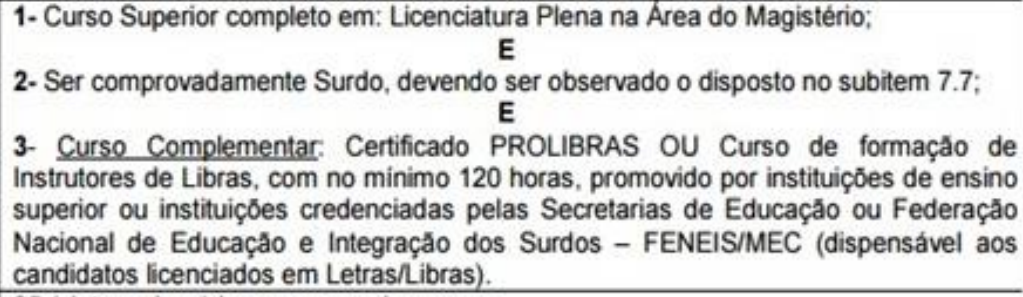 \\
\hline CARGA HORÁRIA: & 25 (vinte e cinco) horas semanais \\
\hline VAGAS & 03 (três) + Cadastro de Reserva \\
\hline \multicolumn{2}{|c|}{ 3.1 - INSTRUTOR DE LIBRAS } \\
\hline REQUISITOS: & $\begin{array}{l}\text { 1- Ensino Médio Completo. } \\
\text { 2- Ser comprovadamente Surdo, devendo ser observado o disposto no subitem 7.7; } \\
\text { 3- Curso Complementar: Certificado PROLIBRAS OU Curso de formaçăo de } \\
\text { Instrutores Surdos, com no minimo } 120 \text { horas, promovido por instituiçōes de ensino } \\
\text { superior ou instituiç̋̄es credenciadas pelas Secretarias de Educaçăo ou Federaçăo } \\
\text { Nacional de Educaçăo e Integraçăo dos Surdos - FENEIS/MEC. }\end{array}$ \\
\hline CARGA HORÁRIA: & 30 (trinta) horas semanais \\
\hline VAGAS & 03 (trés) + Cadastro de Reserva \\
\hline VENCIMENTO & $\begin{array}{l}\text { RS } 1.200,70 \text { de acordo com GRUPO II - CNM, SUBGRUPO B, referente à CLASSE I } \\
\text { REFERENCIA IA. }\end{array}$ \\
\hline
\end{tabular}

Fonte: Edital no 010/2016, de 6 de maio de $2016^{7}$. 
Para uma comparação, apresentamos uma tabela resumida com os seis editais, relacionando-os com o cargo e o requisito e, em seguida, uma breve discussão sobre estes dados:

Tabela 1. Editais

\begin{tabular}{|c|c|c|}
\hline EDITAIS & CARGO & REQUISITO \\
\hline Quadro 1 - Barueri (SP) & Instrutor & $\begin{array}{l}\text { Ensino médio com } \\
\text { magistério + curso de } \\
\text { formação de instrutor de } \\
\text { Libras ou ensino médio + } \\
\text { curso de formação na área } \\
\text { ou ensino superior com } \\
\text { graduação de Pedagogia } \\
\text { ou Licenciatura }\end{array}$ \\
\hline Quadro 2 - Petrópolis (RJ) & Instrutor & $\begin{array}{l}\text { Ensino superior + } \\
\text { Prolibras + Curso de } \\
\text { formação de instrutor de } \\
\text { Libras ou assistente } \\
\text { educacional de Libras }\end{array}$ \\
\hline Quadro 3 - Santo Ângelo (RS) & Instrutor & $\begin{array}{l}\text { Ensino superior na área } \\
\text { da educação + Prolibras }\end{array}$ \\
\hline Quadro 4 - São Caetano do Sul (SP) & Instrutor & $\begin{array}{l}\text { Ensino superior + Curso } \\
\text { específico na área }\end{array}$ \\
\hline Quadro 5 - São Paulo (SP) & $\begin{array}{l}\text { Instrutor (prioritariamente } \\
\text { surdo) }\end{array}$ & $\begin{array}{l}\text { Ensino médio ou } \\
\text { superior + Prolibras ou } \\
\text { Curso de pós-graduação } \\
\text { em Libras }\end{array}$ \\
\hline Quadro 6 - Vitória (ES) & $\begin{array}{l}\text { Instrutor e professor } \\
\text { (comprovadamente surdo) }\end{array}$ & $\begin{array}{l}\text { Instrutor: Ensino médio + } \\
\text { Prolibras ou curso de } \\
\text { formação de instrutores } \\
\text { surdos } \\
\text { Professor: Ensino } \\
\text { superior + Prolibras ou } \\
\text { curso de formação de } \\
\text { instrutores de Libras }\end{array}$ \\
\hline
\end{tabular}

Fonte: Elaborada pelas autoras

A primeira questão que os editais suscitam é sobre a prioridade de vagas para candidatos surdos prevista pelo Decreto $\mathrm{n}^{\mathrm{o}} 5.626 / 2005$. A maioria dos editais não define "a condição auditiva" do candidato. Observa-se que os editais de Barueri (SP), de 
Petrópolis (RJ), de Santo Ângelo (RS) e de São Caetano do Sul (SP) não oferecem vaga para candidatos surdos. Isso significa que uma pessoa ouvinte pode concorrer à vaga de instrutor juntamente com os surdos. Mesmo tendo o Decreto ${ }^{\circ}$ 5.626/2005 estabelecido a prioridade de pessoas surdas para a função de instrutores ou professores de Libras, quatro dos seis editais não mencionam essa prioridade. Somente os editais de São Paulo (SP) e de Vitória (ES) estabelecem que a vaga é prioritariamente para candidatos surdos no cargo de instrutor e professor, respeitando o espaço de mercado de trabalho para esses sujeitos.

A segunda questão que levantamos sobre os editais é em relação à definição do profissional. Os editais 1, 2, 3, 4 e 5 discriminam as vagas para "instrutor". Observando os requisitos, verificamos que os editais 1 e 5 exigem a formação em ensino médio ou superior; os editais 2, 3 e 4 definem como requisito apenas o ensino superior. A questão de requisito dos editais gera certa polêmica. Comparando os seis editais, é visível a violação ao decreto, com exceção dos de São Paulo e Vitória, nos quais a formação mínima exigida para instrutor é a de ensino médio. Se a formação mínima exigida é a de nível superior para o cargo de professor surdo, por que não respeitá-la? Qual a intenção dos editais que colocam o requisito de formação em nível superior para o cargo de instrutor? Não há perspectiva, nem por parte do mercado nem das instituições de ensino, de haver profissionais surdos com ensino superior? Há uma questão ideológica em relação aos surdos no contexto ouvinte? Por que a denominação "instrutor" se mantém para a atividade profissional de ensino de Libras, mesmo na exigência de ensino superior?

Nossa interpretação é que a denominação "instrutor" revela a representação de incapacidade atribuída às pessoas surdas, como se elas não fossem capazes de assumir uma função de professor. Sobre essa desqualificação do profissional surdo, Fernandes (2006) comenta

Ironicamente, alguns dos objetivos e pressupostos de "Milão" sobrevivem no espaço escolar, travestidos em uma nova "roupagem": [...] os surdos adultos são convocados a colaborar no processo educacional, desde que sejam apenas instrutores de Libras, ainda que tenham formação para atuar como professores (FERNANDES, 2006, p. 4).

Outra interpretação para o uso da denominação "instrutor" se refere à própria língua de sinais. Ao denominar de "instrutores" os profissionais que se responsabilizam pelo ensino de Libras nas escolas, atribui-se à língua de sinais um status instrumental. A 
denominação "instrutor" dada àquele que ensina Libras demonstra o quanto a Língua de Sinais ainda é desvalorizada na área educacional, visto que seus professores podem ser comparados àqueles que ensinam algo técnico como dirigir um carro, preparar um prato, praticar uma atividade de recreação ou saltar de paraquedas.

Nessa perspectiva, o conceito de ideologia na concepção bakhtiniana nos ajuda a problematizar os dados apresentados. A ideologia é caracterizada como a expressão, a organização e a regulação das relações histórico-materiais dos homens, portanto pode ser vista como uma representação. Bakhtin afirma que "tudo que é ideológico possui um significado e remete a algo situado fora de si mesmo" (1999, p 31). A ideologia ocorre, segundo Bakhtin, em grupos organizados, assim "não pode derivar da consciência, como pretendem o idealismo e o positivismo psicologista, pois a consciência adquire forma e existência nos signos criados por um grupo organizado no curso de suas relações sociais (BAKHTIN, 1999, p.35)".

Como afirma Bakhtin (1999), a ideologia tem "dupla face". Reflete uma coisa, mas refrata outra, por meio de signo, que é visto como um todo, um produto ideológico, e não existe como uma parte da realidade. De acordo com esse autor, todo signo é ideológico.

Nesse caso, o edital, com suas especificidades, define que o candidato somente poderá assumir o posto se for aprovado no concurso público (ou na seleção, no caso do credenciamento) e atender a todos os requisitos estabelecidos no documento. No entanto, não se respeitam as vagas para candidatos surdos. De seis quadros, apenas dois preveem a prioridade para candidato surdo. O quadro 6 - edital de Vitória - segue as normas do decreto dentro do quadro exigido pelo edital, assim cumprindo legalmente a formação própria e específica para a docência, o que caracteriza um aspecto positivo em questão de respeito e legalidade para o espaço da pessoa surda, o que é valorizado e reforçado pela demanda de atuação dos docentes na educação básica.

Outro aspecto relevante para a discussão é a docência da disciplina de Libras em ensino superior. $O$ artigo $7^{\circ}$ do Decreto $n^{\circ} 5.626 / 2005$ estabelece três perfis de profissionais para ministrar a disciplina de Libras nos dez anos seguintes à sua promulgação.

Contextualizando o cenário atual da educação de surdos com os editais e o decreto, destacamos as palavras de Maher (2007), pesquisadora da área de línguas minoritárias como línguas indígenas, de fronteira, de imigrantes, de sinais e outras. A autora ressalta 
a importância de programas voltados para as especificidades linguístico-culturais de grupos minoritários:

[...] não basta as minorias brasileiras [...] terem consciência de seus direitos para que o cenário de opressão linguístico-cultural em que vivem seja, na prática, no varejo, no cotidiano, modificado. Daí o meu desconforto com o modo como o termo empoderamento vem sendo, em muitas situações, utilizado. Creio que os termos politização ou fortalecimento político dos grupos sociais destituídos de poder traduzem melhor o que buscamos com nossas pesquisas e ações educativas (MAHER, 2007, p. 257).

A autora destaca as três principais ações que necessitam de ação coletiva para a resolução desse problema educacional brasileiro: I - Politização: necessita de grupos de debates, movimentos políticos e sociais e associações de surdos, entre outros, que possam discutir a importância do professor surdo escolas de surdos enfatizando o processo de ensino e aprendizagem do aluno surdo de forma e ter a comunicação "plena" entre docente e estudantes; II - Estabelecimento de legislações: necessita urgentemente de reestruturação do Decreto $n^{\circ} 5.626 / 2005$, visto que sua criação, há mais de dez anos, ocorreu em um momento em que ainda havia poucos surdos formados. Essa reestruturação deveria rever principalmente os aspectos referentes à formação e à docência. Em outras palavras, se na atualidade existem vários surdos formados em cursos de graduação e pós-graduação na área de Libras, por que as mudanças nas formas de contratação dos surdos caminham vagarosamente? Ou seja, o que justifica a permanência do cargo de "instrutor" para ministrar a disciplina de Libras no ensino superior?; III Educação do entorno: trata-se da necessidade de uma efetiva mudança no ensino para surdos, o respeito à profissão do professor surdo e a inclusão da disciplina de Libras na grade curricular para garantir o "fortalecimento", o reconhecimento e o respeito às pessoas surdas.

Vale ressaltar que o Decreto $n^{\circ}$ 5.626/ 2005 também dispõe sobre a formação do tradutor e intérprete de Libras/língua portuguesa "e o direito dos surdos de ter acesso às informações em Libras e à educação bilíngue" (LACERDA; ALBRES; DRAGO, 2013, p. 3). Enquanto a política educacional insiste na educação inclusiva, muitas crianças estão sem direito ao acesso à sua língua, sem direito linguístico, pois muitas escolas ainda não têm uma estrutura de ensino bilíngue. Poucos professores ouvintes sabem Libras e se ainda não há intérpretes suficientes, ainda menor é a presença do professor surdo na sala 
de aula. Quando há intérpretes em sala de aula, a criança está inserida em um ambiente em que não há trocas entre os pares e com pouco acesso à língua, impossibilitando uma real aquisição da linguagem.

\section{Conclusões}

A problematização, neste artigo, da utilização da nomenclatura "instrutor surdo" na contratação de educadores surdos em algumas redes públicas de ensino, coloca em evidência a manutenção de uma visão preconceituosa em relação às pessoas surdas e à língua de sinais. A subsistência da ideia de incapacidade do surdo e da instrumentalização da língua de sinais, embutidas na ideia de um "instrutor de Libras" é ainda uma realidade na educação dos surdos. Apesar de as leis terem avançado de acordo com as reivindicaçoes dessa minoria, sua implementação pelas políticas públicas dos municípios e estados brasileiros se mantém em um paradigma arcaico, já que essas leis pouco avançaram em relação à epoca da hegemonia do oralismo, ou seja, desde o Congresso de Milão (1880) até em torno do final do século XX.

A mudança radical desse paradigma necessita de uma compreensão de que a Libras é uma língua e que, portanto, para sua aquisição, as crianças surdas precisam de interlocutores competentes e de educadores que a utilizem em todo o processo educacional. Necessita-se ainda compreender que as pessoas surdas, graduadas em cursos de formação de professores, são capazes de orientar as crianças surdas em todos as suas necessidades educativas, sendo, portanto, professores e não "instrutores".

Faz-se cada vez mais premente pensarmos sobre a necessidade de construir uma prática educativa inovadora, pautada na construção e reflexão da formação do profissional surdo, que lhe dê a possibilidade de agir, transformar e refletir sobre a prática educativa dos docentes. É preciso, pouco a pouco, através dos desafios do contexto em que se vive, olhar e perceber os obstáculos como possibilidades de construção do novo.

Para que essas mudanças aconteçam e a escola consiga exercer seu papel, é necessário que todos caminhem juntos, surdos e ouvintes, visando a construção de uma educação de qualidade para crianças, jovens e adultos surdos com professores, diretores e pesquisadores surdos. É necessário criar condições e visibilidade para o profissional educador surdo. 


\begin{abstract}
The purpose of this paper is to present questions concerning the profession of the deaf educator, examining the legislation, especially regarding the employment relationship, because many deaf professionals, trained and qualified as teachers, are hired as instructors. To problematize the expression "Libras instructor", attributed to deaf professionals who teach Libras, we have analyzed public tenders that bring in their text the expression "deaf instructor". We defend the autonomy of the teacher in his pedagogical practices, anchored in a specific formation and we emphasize the need to differentiate the terms "Libras instructor" and "teacher", to value the teaching work and, above all, to give visibility and space to the deaf teacher.
\end{abstract}

Keywords: Deaf teachers. Bilingual deaf education. Teaching practice.

\title{
Referências
}

BAKHTIN, Mikhail. Marxismo e filosofia da linguagem: problemas fundamentais do método sociológico na ciência da linguagem. 9. ed. São Paulo: Hucitec, 1999.

BRASIL. Decreto $\mathbf{n}^{\circ}$ 5.626/2005. Regulamenta a Lei ${ }^{\circ} 10.436$ de 24 de abril de 2002, que dispõe sobre a Língua Brasileira de Sinais (Libras). Brasília, DF, 2005. Disponível em: < http://www.planalto.gov.br/ccivil 03/ ato2004-2006/2005/decreto/d5626.htm> . Acesso em: 13 abr.2016.

BOTELHO, Paula. Segredos e silêncios na educação dos surdos. Belo Horizonte: Autêntica, 1998.

FERNANDES, Sueli. Práticas de letramentos na educação bilíngue para surdos. Curitiba: SEED, 2006. Disponível em: http://www.cultura-sorda.org/wpcontent/uploads/2015/03/Fernandes_praticas_letramentos-surdos_2006.pdf. Acesso em: 27 de mar. de 2016.

LACERDA, Cristina Broglia Feitosa. A criança surda e a língua de sinais no contexto de uma sala de aula de alunos ouvintes. Relatório parcial do projeto de pesquisa FAPESP. Proc. nº 98/02861-1, 1999.

LACERDA, Cristina Broglia Feitosa; ALBRES, Neiva Aquino; DRAGO, Silvana. Política para uma educação bilíngue e inclusiva a alunos surdos no município de São Paulo. Educ. Pesqui., São Paulo, v. 39, n. 1, p. 65-80, jan./mar. 2013. Disponível em: http://www.scielo.br/pdf/ep/v39n1/v39n1a05.pdf. Acesso em: 25 de set. de 2016.

LIBÂNEO, José Carlos. Didática. São Paulo: Cortez, 1994.

MAHER, Terezinha de Jesus Machado. A educação do entorno para a interculturalidade e o plurilinguismo. In: KLEIMAN, A. B.; CAVALCANTI, M. C. (orgs.). Linguística aplicada: suas faces e interfaces. Campinas, SP: Mercado de Letras, 2007, p. 255-270. 
MARTINS, Vanessa Regina de Oliveira e LACERDA; Cristina Broglia Feitosa. Educação inclusiva bilíngue para surdos: problematizações acerca das políticas educacionais e linguísticas. Rev. educ. PUC-Camp., Campinas, 21(2):163-178, maio/ago., 2016.

REIS, Flaviane. Professores surdos: identificação ou modelo? In: QUADROS, R. M. de; PERLIN, G. (Org.). Estudos Surdos II. Rio de Janeiro: Arara Azul, 2007. Disponível em: http://www.librasgerais.com.br/materiais-inclusivos/downloads / Estudos - SurdosII.pdf. Acesso em: 23 de abr. de 2016.

SAVIANI, Demerval. Os saberes implicados na formação do educador. In: BICUDO, Maria Aparecida; SILVA JUNIOR, Celestino Alves (orgs.). Formação do educador: dever do Estado, tarefa da Universidade. São Paulo: Unesp, 1996.

TARDIF, Maurice. Saberes docentes e formação profissional. $11^{\mathrm{a}}$ Edição. Petrópolis: Editora Vozes, 2010.

VYGOTSKY, Lev Semenovitch. A formação social da mente: o desenvolvimento dos processos psicológicos superiores. 6 ed. São Paulo: Martins Fontes, 1998.

\footnotetext{
${ }^{1}$ A certificação de proficiência em Libras foi realizada pelo Ministério de Educação e Cultura, através do exame PROLIBRAS, que foi realizado até o ano de 2015. Informação disponível em http://www.consultaesic.cgu.gov.br.

2 Disponível: https://www.pciconcursos.com.br/concurso/prefeitura-de-barueri-sp-40-vagas

${ }^{3}$ Disponível em: https://www.pciconcursos.com.br/noticias/prefeitura-de-petropolis-rj-retifica-concursopublico-para-a-area-da-educacao.

${ }^{4}$ Disponível em: https://www.pciconcursos.com.br/concurso/prefeitura-de-santo-angelo-rs-75-vagas

${ }^{5}$ Disponível em: https://arquivo.pciconcursos.com.br/prefeitura-de-sao-caetano-do-sul-sp-altera-edital-doconcurso-com-mais-de-880 vagas/1341939/64a280e421/edital_de_abertura_n_001_2015.pdf

6 Disponível em: https://www.imprensaoficial.com.br/DO/BuscaDO2001Documento_11_4.aspx?link= /2016/diario\%2520oficial\%2520cidade\%2520de\%2520sao\%2520paulo/abril/27/pag_0076_894MDRIML IU3GeDODVTENKOG5CK.pdf\&pagina=76\&data=27/04/2016\&caderno=Di\%C3\%A1rio\%20Oficial\%2 0Cidade\%20de\%20S\%C3\%A3o\%20Paulo\&paginaordenacao $=100076$

${ }^{7}$ Disponível em: https://arquivo.pciconcursos.com.br/prefeitura-de-vitoria-es-anuncia-tres-processosseletivos/1355924/1157023f00/edital_de_abertura_n_10_2016.pdf
} 